\title{
Open lung biopsy in patients with diffuse pulmonary shadowing
}

\author{
GE VENN, PH KAY, CJ MIDWOOD, P GOLDSTRAW
}

From Brompton Hospital, London

ABSTRACT The radiological appearances of diffuse pulmonary shadowing are not specific and frequently histological examination is necessary to provide a diagnosis or assess the activity of the disease. From July 1979 to May 1983 open lung biopsy was performed in 101 patients through a limited submammary incision. Twenty seven patients had undergone prior invasive investigations and 27 were taking corticosteroids at the time of biopsy. In 92 patients the histological appearances after open lung biopsy were sufficiently specific to permit diagnosis. Respiratory tract infection occurred in six patients and in eight there was some superficial infection of the wound. These complications were more frequent in patients taking corticosteroids but the difference was not statistically significant. The chest drain was removed usually on the first postoperative day. In three critically ill patients an air leak occurred after removal of the drain, requiring formal surgical re-exploration and drainage in two cases and a brief period of intercostal drainage in the third. Four patients in the series died. All had severe pre-existing lung disease; in three open lung biopsy was performed in the late stages of severe, rapidly progressive lung disease eluding diagnosis; the fourth patient, who had massive pulmonary fibrosis from asbestos lung disease, developed a respiratory tract infection and died from progressive respiratory failure. Open lung biopsy can be performed with minimal morbidity and a high diagnostic yield. The approach used in this series provides a safe and reliable operation with good cosmetic results.

Diffuse pulmonary shadowing is a radiological feature of many disease processes, which remain undiagnosed despite extensive inpatient investigation. This has led to the need for a satisfactory method of obtaining representative lung tissue as a basis for a histological diagnosis and appropriate treatment.

It is now 100 years since the aspiration of material containing bacterial organisms was performed by Leyden. ${ }^{1}$ Various techniques have since evolved for obtaining pulmonary tissue. Those in common use are aspiration needle biopsy, ${ }^{1}$ drill biopsy, ${ }^{2}$ transbronchial biopsy, ${ }^{3}$ and open lung biopsy. ${ }^{4}$

High histological yields are produced by aspiration needle biopsy and drill biopsy in those patients with discrete pulmonary masses. Transbronchial biopsy produces similarly high yields with a lower level of morbidity, notably in patients with sarcoidosis. The histological yield of all these methods is significantly reduced, however, in patients with diffuse pulmonary

Address for reprint requests: Mr P Goldstraw FRCS, Brompton Hospital, London SW3.

Accepted 15 July 1985 shadowing. ${ }^{5-8}$ Open lung biopsy has previously been shown to give a higher diagnostic yield in such patients. $^{7-14}$

We have therefore reviewed 101 cases in which we have used a modified version of the original technique of Klassen ${ }^{4}$ to produce a method of open lung biopsy that combines the provison of representative tissue for histological analysis with a low level of morbidity and a satisfactory cosmetic result. All biopsy samples were taken by a standard technique under the supervision of one consultant surgeon (PG).

All patients in this series were operated on at the Brompton Hospital, which acts as a national secondary referral centre for cases of chronic lung disease eluding diagnosis; the patients therefore tend to represent the more chronic and severe end of the disease range.

\section{Methods}

One hundred and one patients with diffuse intrapulmonary shadowing underwent open lung biopsy fom July 1979 to May 1983: 66 patients were male and 
Histological diagnoses established by open lung biopsy

\begin{tabular}{ll}
\hline Diagnosis & No of cases \\
\hline Main conditions & 51 \\
Cryptogenic fibrosing alveolitis & 7 \\
Sarcoidosis & 5 \\
Lymphagitis carcinomatosa & 4 \\
Lymphoma & 3 \\
Churg Strauss syndrome & 3 \\
Asbestos lung disease & 2 \\
Extrinsic allergic alveolitis & 2 \\
Chronic obstructive lung disease & 2 \\
Alveolar proteinosis & 2 \\
Infective conditions & 1 \\
Organising pneumonia & 1 \\
Eosinophilic pneumonia & 1 \\
Cytomegalovirus pneumonia & 1 \\
Nocardia infection & \\
Actinomycosis & \\
Miscellaneous conditions (One case of each) & \\
Wegener's granulomatosis, histiocytosis X, amiodorone lung, \\
hardmetal lung disease, graft versus host reaction, \\
eosinophilicgranuloma, multiple pulmonary infarcts
\end{tabular}

35 female, with ages ranging from 23 to 73 (mean 47) years. The length of the history before open lung biopsy ranged from two weeks to 10 years with a median of 12 months.

Twenty seven patients had undergone invasive investigation before open lung biopsy ( 23 patients by transbronchial biopsy, three by drill biopsy, and one by both transbronchial biopsy and drill biopsy). Twenty seven patients were taking corticosteroids at the time of operation at a dose ranging from 10 to 60 mg prednisolone (median $30 \mathrm{mg}$ ). The incidence of complications in those receiving and not receiving steroids was evaluated by Fisher's exact test.

\section{OPERATIVE TECHNIQUE}

A 4-10 cm anterolateral thoracotomy is made with the patient lying supine and a sandbag raising the side of operation. The right side of the chest is chosen if the disease appears symmetrical. The skin incision is made in the submammary skin fold for the best cosmetic effect. The incision is then deepened by application of diathermy to the chest wall and the chest is opened through an adjacent interspace, the level of which is adjusted according to the loss of lung volume apparent on the chest radiograph. Retraction of the costal cartilages allows inspection of the anterior aspects of all lobes as the well as the mediastinum, pleura, and diaphragm. A representative portion of underlying lung tissue is then secured with a right angle crushing clamp. Normal anaesthetic ventilation is maintained throughout this time with no attempt either to collapse or to hyperinflate the lung. A running suture of $3 / 0$ Prolene is inserted proximal to the clamp and the specimen is cut free. The clamp is then removed and the running suture tied. A further biopsy specimen is then secured from an area of macroscopically unaffected lung, for histological com- parison between this and the diseased lung tissue. A single chest drain is inserted through the interspace below and the wound is closed in layers with polyglycolic acid polymer sutures. Skin closure is performed with a subcuticular $2 / 0$ suture for an optimal cosmetic result. The chest drain is placed on $2 \mathrm{kPa}$ suction and removed the following morning.

\section{Results}

Open lung biopsy provided diagnostic histological material yielding a diagnosis in 92 of the 101 cases (table), cryptogenic fibrosing alveolitis being the most common diagnosis. In the remaining nine patients the histological findings were not sufficient for a firm diagnosis to be made.

Of the 27 patients investigated invasively before open lung biopsy a histological diagnosis had been established in seven (figure). Four of these diagnoses were confirmed but the other three proved incorrect and were amended by open lung biopsy, being changed respectively from organising pneumonia, interstitial pneumonia, and idiopathic pulmonary haemosiderosis to lymphoma in the first case and cryptogenic fibrosing alveolitis in the other two. A definitive diagnosis was provided for the first time in 14 other patients in this group; in the remaining six no firm histological diagnosis was established by either open lung, transbronchial, or drill biopsy.

\section{MORBIDITY AND MORTALITY}

Respiratory tract infection requiring physiotherapy and antibiotics occurred in six patients, three of whom were taking corticosteroids at the time of surgery. Superficial wound infection requiring wound toilet or antibiotic treatment, or both, occurred in eight

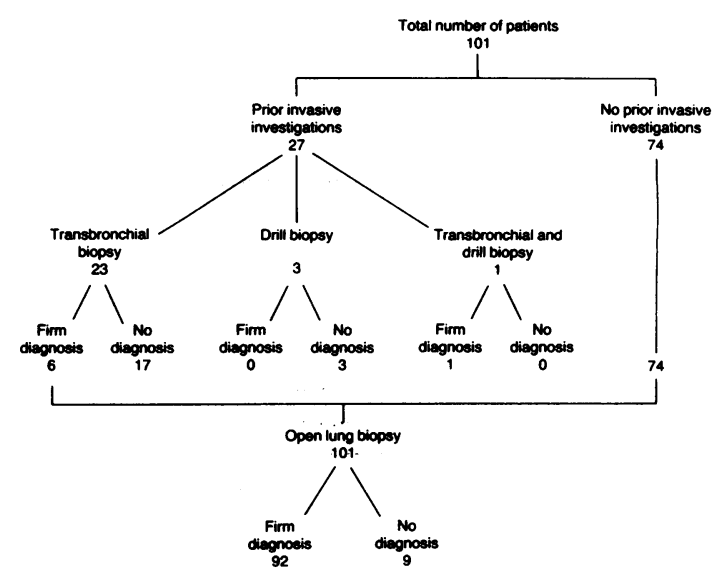

Diagnosis resulting from investigations in the 101 patients. 
patients, four of whom were taking steroids. There was, however, no statistical difference in the incidence of either respiratory tract or wound infection between those who were receiving corticosteroids and those who were not. In one patient re-exploration of the chest was performed for postoperative haemothorax. At operation the bleeding was found to be arising from the chest wall and not the lung biopsy site. Four patients died within 30 days of open lung biopsy and are therefore considered in detail.

Patient $A$, a 45 year old woman, presented with a rapidly progressive "pneumonic" illness thought initially to be tuberculous in origin, and received conventional triple antibiotic treatment. Her condition rapidly deteriorated, however, to the point of requiring ventilation with $100 \%$ oxygen and a minute volume of 16 litres to achieve arterial oxygen tension $\left(\mathrm{PaO}_{2}\right)$ of $12 \mathrm{kPa}$. No definite diagnosis had been obtained despite repeated sputum culture, viral serology, and transbronchial biopsy. In view of her critical state high dose corticosteroid treatment was started at a dose of $60 \mathrm{mg}$ prednisone per day but no improvement occurred and open lung biopsy was undertaken. Histological examination showed a chronic interstitial pneumonia with massive parenchymal destruction, of suspected viral origin. The patient developed a small pneumothorax in the early postoperative period, which responded to intercostal drainage; but her underlying condition continued to deteriorate and she died three days after surgery. Necropsy confirmed the biopsy findings but did not identify a cause.

Patient $B$, a 40 year old man, had developed acute myeloblastic leukaemia and received whole body irradiation, cytotoxic drugs, and a subsequent bone marrow graft. He presented six months after treatment with recent onset, rapidly progressive shortness of breath and diffuse miliary shadowing on the chest radiograph. He was dyspnoeic at rest breathing room air $\left(\mathrm{PaO}_{2} 9.4 \mathrm{kPa}\right.$, arterial carbon dioxide tension $\left.\left(\mathrm{PaCO}_{2}\right) 3.9 \mathrm{kPa}\right)$. No diagnosis had been obtained from sputum culture or transbronchial biopsy. Open lung biopsy was performed and histological examination showed a graft versus host reaction. Treatment was started with high dose methyl prednisolone. During the ensuing two weeks he developed increasing respiratory difficulty, requiring an inspired oxygen concentration of $60 \%$, initially by face mask but subsequently by intermittent positive pressure ventilation. Eighteen days after the operation he developed a pneumothorax, with a persistent air leak, on the side of surgery, requiring re-exploration. The leak was found to be remote from the site of biopsy. After this he continued to require ventilatory support and deteriorated, dying eight days after the reexploration. Necropsy confirmed the diagnosis of severe graft versus host reaction.

Patient $C$, a 50 year old man, had been treated previously for polycythaemia rubra vera with P32 and busulphan and presented with a two month history of progressive debilitating shortness of breath. The radiograph showed diffuse reticular shadowing and respiratory function tests indicated a severe ventilatory defect-FEV 1 of 1.351 (41\% of predicted), forced vital capacity $1.71(38 \%)$, transfer factor (TLCO) $1.36 \mathrm{mmol} \mathrm{min}{ }^{-1} \mathrm{kPa}^{-1}(21 \%)$ and transfer coefficient (KCO) $0.39(38 \%)$. Open lung biopsy was performed; on the second postoperative day the patient suffered a cardiac arrest and could not be resuscitated. Necropsy showed widespread areas of old and fresh pulmonary infarcts and the features of polycythaemia rubra vera.

Patient $D$, a 54 year old man, presented with a three year history of gradually progressive shortness of breath $\left(\mathrm{PaO}_{2} 7.47 \mathrm{kPa}\right.$ with $60 \%$ oxygen by face mask, with $\mathrm{PaCO}_{2}$ of $4.9 \mathrm{kPa}$ ). Respiratory function tests indicated a predominantly restrictive defect- $-\mathrm{FEV}_{1}$ $1.91(55 \%)$, FVC $2.11(48 \%)$, TLCO $0.80(8 \%)$, and Kco 0.29 (18\%). The patient proceeded to open lung biopsy and made a satisfactory initial recovery, but subsequently developed a Haemophilus chest infection, which was treated with appropriate antibiotics. His respiratory state continued to deteriorate and he required ventilatory support 72 hours after surgery; high dose corticosteroids were started at this time. Five days later he developed a pneumothorax with a persistent air leak, requiring surgical re-exploration. The leak was found to be at the site of previous biopsy and was repaired. This leak, however, recurred two days later. The patient continued to require ventilatory support and deteriorated, dying four weeks after the initial surgery.

\section{Discussion}

In keeping with the findings from other series we have found that open lung biopsy is capable of producing a high diagnostic yield $(91 \%)$ in patients with diffuse pulmonary disease. ${ }^{5-1012-14}$

Aspiriation needle and drill biopsy produce similarly high yields (81-95\%) in discrete and notably neoplastic disease, ${ }^{21516}$ but lower yields in patients with diffuse disease. ${ }^{5-8}$ Despite being less invasive than other forms of biopsy, of both aspiration needle biopsy and drill biopsy tend to produce appreciable morbidity, notably in the form of pneumothorax $(20-46 \%), 56815-18$ which may be prolonged in older patients. $^{915}$ Transbronchial biopsy provides a higher 
diagnostic yield in patients with diffuse disease $(59-80 \%)^{818-20}$ with considerably less morbidity $(2-9 \%))^{318192122}$ which is largely in the form of clinically unimportant haemoptysis. Open lung biopsy, however, produces considerably higher diagnostic yields $(65-100 \%)$ in patients with diffuse disease, with a low level of morbidity $(1-8 \%),{ }^{5-14}$ our own figures being in accordance with previous experience.

Burt et $\mathrm{al}^{7}$ advocate the addition of transbronchial biopsy to open lung biopsy as in their series this increased the diagnostic yield. We have not routinely added this to our operative procedure; in the 24 patients in whom transbronchial biopsy was performed before open lung biopsy this produced no increase in our diagnostic yield and we are thus reluctant to add this to the operative procedure.

Of the four deaths occurring in this series, three were in a group presenting with a rapidly progressive, overwhelming disease with severe pulmonary dysfunction as a primary of secondary feature. In no case had any treatable condition been diagnosed despite extensive investigation. Two patients (A and B) were considered to be dying unless a treatable condition could be diagnosed. All those dying had been receiving high dose corticosteroids, producing some degree of immunosuppression, during the course of their illness. The increased morbidity and mortality associated with all forms of lung biopsy in this group is well documented, ${ }^{51113}$ with a 30 day hospital mortality rate as high as $31 \% .^{5}$ In few patients is death directly attributable to surgical intervention, the patients succumbing from progression of their disease after biopsy. Open lung biopsy, however, still produces the highest diagnostic yield in this group $(71 \%-100 \%)^{11-13}$ Postoperative pneumothorax occurred in three of the four patients who died all of whom were requiring intermittent positive pressure ventilation at the time of the air leak. No other patient developed a secondary air leak. The higher incidence of such leaks in immunocompromised patients and those requiring intermittent postive pressure ventilation is noted by other workers. ${ }^{51113}$ The severely ill immunocompromised patient therefore represents a special and difficult problem. The severity of their disease and the high mortality rate in the absence of a diagnosis and treatable condition makes diagnosis imperative. In such patients open lung biopsy offers the highest likelihood of obtaining a definitive diagnosis and this must be weighed against the attendant risks by the clinician in each case.

Our technique has evolved by modifying the method reported by Klassen ${ }^{4}$; simplifying the suture technique for the biopsy site, avoiding the use of multiple clamps for securing the pulmonary tissue, and allowing normal anaesthetic ventilation throughout the procedure rather than hyperinflating and thus herniating the lung through the chest wall incision, which hinders both exploration of the pleural cavity and mediastinum and the isolation of representative pulmonary tissue. We have avoided taking biopsy specimens from areas of severe disease or fibrosis as these frequently lack the diagnostic features of the original disease. $^{10}$ We advocate the routine use of postoperative chest drainage for 12-24 hours to avoid the high incidence of complications in the form of pneumothorax, hydrothorax, and subcutaneous emphysema reported by others. ${ }^{2324}$

We have found this method of lung biopsy to provide a high diagnostic yield where other biopsy methods have failed. The morbidity rate is low and remains acceptable even when high dose corticosteroids are being given. Mortality is strongly associated with those presenting with an acute, rapidly progressive pulmonary disease and this group represents a high risk category, as distinct from those with the more typical slowly progressive, diffuse pulmonary disease, in whom open lung biopsy combines high diagnostic yeld with minimal morbidity. The approach we have chosen provides access to the anterior aspects of upper, middle, and lower lobes, permits representative biopsy of these areas, and produces a highly satisfactory cosmetic result.

We thank the physicians of the Brompton Hospital for providing their patients and allowing us to present these data.

\section{References}

1 Leyden. Verhandlungen des Vereins für innere Medicin. Disch Med Wochensch 1983;9:52.

2 Steel SJ, Winstanley DP. Trephine biopsy of the lung and pleura. Thorax 1969;24:576-84.

3 Anderson HA, Fontana RS. Transbronchoscopic lung biopsy of diffuse pulmonary disease. Chest 1972; 62:125-8.

4 Klassen KP, Anlyana AJ, Curtis GM. Biospy of diffuse pulmonary lesions. Arch Surg 1949;59:694-704.

5 Greenman RL, Goodall PT, King D. Lung biopsy in immunocompromised hosts. Am J Med 1975;59:488-96.

6 Woolf CR. Application of aspiration lung biopsy with a review of the literature. Dis Chest 1954;25:286-301.

7 Burt ME, Wayne Flye M, Webber BL, Path FF, Wesley RA. Prospective evaluation of aspiration needle, cutting needle, transbronchial and open lung biopsy in patients with pulmonary infiltrates. Ann Thorac Surg 1981; 32:146-51.

8 Gaensler EA, Moister MVB, Hamm J. Open biopsy in diffuse pulmonary disease. $N$ Engl $J$ Med 1964; 270:1319-31.

9 Gaensler EA, Carrington CB. Open biopsy for chronic diffuse infiltrative lung disease. Ann Thorac Surg 1980;30:411-24.

10 Sattersfied JR, McLaughlin JS. Open lung biopsy in diagnosing pulmonary infiltrates in immunosuppressed 
patients. Ann Thorac Surg 1979;28:359-62.

11 Robak SA, Weintraub EH, Nesbit M, Spanos PK, Burke B, Leonard A. Diagnostic open lung biopsy in the critically ill child. Pediatrics 1973;52:605-8.

12 Leight GS, Michaelis LL. Open lung biopsy for the diagnosis of acute, diffuse pulmonary infiltrates in the immunosuppressed patient. Chest 1978;73:477-82.

13 Aaron BL, Bellinger SB, Shepard BM, Doohen DJ. Open lung biopsy: a strong stand. Chest 1971;59:18-22.

14 Nealon TF, Kramer M. Biopsy of the lung. Ann Thorac Surg 1981;32:214-5.

15 Sagel SS, Ferguson TB, Forrest JV, Roper CL, Weldon CS, Clark RE. Percutaneous transthoracic needle biopsy. Ann Thorac Surg 1978;26:399-403.

16 Feist JH. Letter to the editor. Chest 1977;69:244.

17 Boylen CT, Johnson NR, Richters V, Balchum OJ. High speed trephine lung biopsy: methods and results. Chest 1973;63:59-62.

18 Smith CW, Murray GF, Wilcox BR, Starek PJK, Delany
DJ. The role of transbronchial lung biopsy in diffuse pulmonary disease. Ann Thorac Surg 1977;24:54-8.

19 Clark RA, Gray PB, Townsend RH, Howard P. Transbronchial lung biopsy: a review of 85 cases. Thorax 1977;32:546-9.

20 Ellis $\mathrm{JH}$. Transbronchial lung biopsy via the fibreoptic bronchoscope. Chest 1975;68:524-31.

21 Zavala DC. Pulmonary haemorrhage in fibreoptic transbronchial biopsy. Chest 1976;50:584.

22 Mitchell DM, Emerson CJ, Collins JV, Stableforth DE. Transbronchial lung biopsy with the fibreoptic bronchoscope: Analysis of results in 433 patients. Br J Dis Chest 1981;75:258-62.

23 Klassen KP, Andrews NC. Biopsy of diffuse pulmonary lesions: a seventeen year experience. Ann Thorac Surg 1967;4:117-25.

24 Theodos PA, Allbritten FF, Breckenridge RL. Lung biopsy in diffuse pulmonary disease. Dis Chest 1955; 27:637-48. 